\section{Edema pulmonar no cardiogénico recurrente tras la administración oral de hidroclorotiazida}

\section{Recurrent non-cardiogenic lung edema secondary to the oral administration of hydrochlorothiazide}

La hidroclorotiazida (HCT) es un diurético de la familia de las tiazidas muy empleado para la hipertensión arterial sistémica (HTA) y estados edematosos ${ }^{1}$. Son bien conocidos sus efectos secundarios más comunes como: alteraciones electrolíticas, debilidad, espasmos musculares, trastornos gastrointestinales e hiperuricemia. Pero hay descritas reacciones idiosincrásicas menos frecuentes y de mayor gravedad como hipotensión y edema agudo pulmonar (EAP).

Presentamos el caso de una paciente que desarrolló un cuadro de hipersensibilidad a HCT consistente en EAP no cardiogénico.

Se trata de una mujer de 83 años sin alergias medicamentosas conocidas, HTA de larga evolución en tratamiento con bloqueantes de receptores $\mathrm{AT}_{1}$ de la angiotensina II, diabetes mellitus tipo 2 , dislipidemia, hemorragia digestiva secundaria a úlcera duodenal hace años y artrosis generalizada.

Por mal control de su HTA su médico de atención primaria le cambia su antihipertensivo habitual por una asociación de losartán e HCT. Al poco tiempo de la toma del nuevo medicamento presenta náuseas, dolor abdominal y disnea. Es trasladada a la urgencia de nuestro centro encontrándose hipotensa, sudorosa, con trabajo respiratorio e hipoxémica a pesar de oxigenoterapia, adrenalina, broncodilatadores y corticoides. Dada la insuficiencia respiratoria grave ingresa en UCI. En la analítica destaca 2.700 leucocitos/ $\mu$ l con predominio de neutrófilos y acidosis metabólica $\left(\mathrm{pH} 7,18 ; \mathrm{HCO}_{3}\right.$ $18 \mathrm{mEq} / \mathrm{l}$; láctico 5,2 mmol/l), CPK MB pico de $3,8 \mathrm{ng} / \mathrm{dl}$, $\mathrm{TpT}<0,01 \mathrm{ng} / \mathrm{ml}$. PAFI 160, radiografía de tórax con infiltrados intersticiales bilaterales más marcado en hemitórax derecho compatible con EAP (fig. 1). En el ECG presenta taquicardia sinusal a 120 lat/min con infradesnivelación de ST en cara lateral. En el ecocardiograma se observa hipertrofia concéntrica con buena fracción de eyección sin alteraciones de la contractilidad segmentaria. Presión venosa central de $6 \mathrm{mmHg}$. Se inicia ventilación mecánica no invasiva (VMNI) con $\mathrm{FiO}_{2} 100 \%$, noradrenalina, bicarbonato y furosemida. A las pocas horas presenta mejoría respiratoria y hemodinámica pudiéndose suspender la VMNI y el soporte vasoactivo progresivamente. Revisando su historia clínica encontramos que siete años antes presentó dos episodios, separados por siete meses, de insuficiencia respiratoria e hipotensión tras el cambio de su medicación habitual por HCT asociada a otro antihipertensivo. En los dos casos la radiografía mostraba infiltración alvéolo-intersticial y ambos episodios fueron autolimitados, diagnosticándose dichos episodios de infección respiratoria e hipotensión secundaria a vasodilatadores. Ante dichos hallazgos en sus antecedentes y el cuadro clínico actual se diagnosticó de EAP no cardiogénico secundario a HCT.

El EAP puede clasificarse según su origen, en cardiogénico, por aumento de la presión hidrostática vascular, o

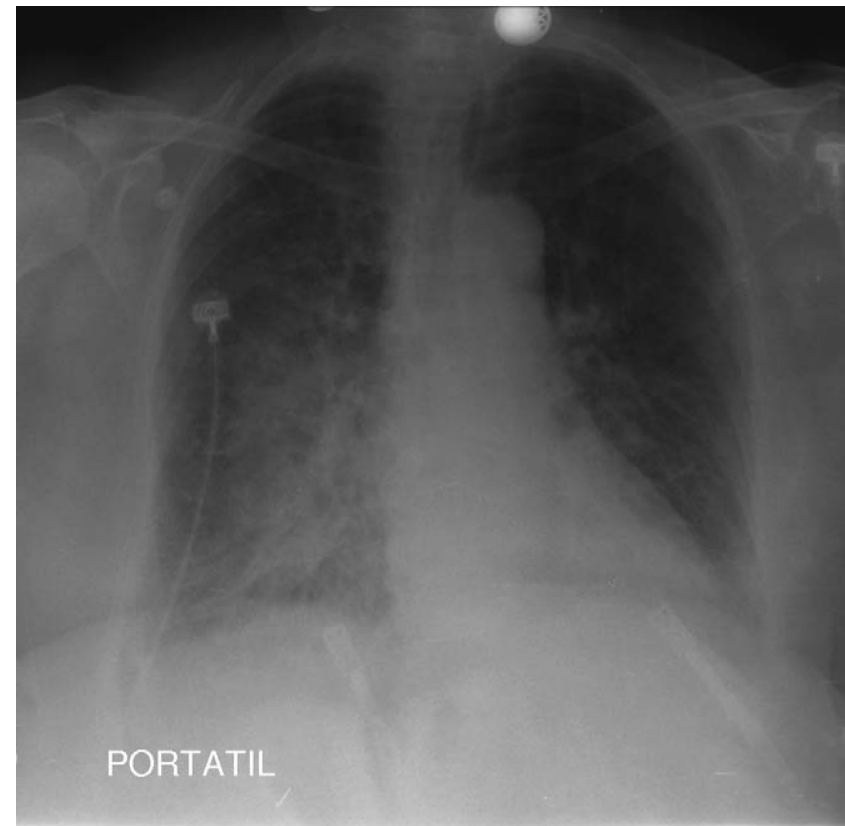

Figura 1 Infiltrados alveolo-intersticiales bilaterales compatibles con EAP.

no cardiogénico, por aumento de la permeabilidad vascular pulmonar. El síndrome de dificultad respiratoria aguda del adulto (SDRA) es una forma no cardiogénica de EAP, debiendo cumplir los criterios de la Conferencia de Consenso americana-europea para el SDRA ${ }^{2}$. Existen numerosos factores de riesgo para desarrollar EAP no cardiogénico como sepsis, politraumatismos, pancreatitis y fracaso multiorgánico, entre otros. El EAP no cardiogénico secundario a fármacos es infrecuente, correspondiendo al $3 \%$ de los casos $^{3}$. El primer caso de EAP no cardiogénico por HCT fue descrito por Steinberg en $1968^{4}$. Esta complicación es más frecuente en mujeres ${ }^{5}$, mayoritariamente entre la quinta y sexta década y acontece en los primeros $60 \mathrm{~min}$ tras la toma del medicamento. El cuadro suele ser inespecífico, describiéndose disnea, cianosis, dolor abdominal, náuseas y vómitos. Hasta un tercio de los casos presenta fiebre autolimitada en las primeras $24 \mathrm{~h}$ con o sin leucocitosis. En los episodios recurrentes la gravedad del cuadro aumenta como sucede en nuestro caso.

La etiopatogenia sigue siendo desconocida. Manso et al defienden la teoría de una reacción alérgica tipo I por reactivación de basófilos e $\operatorname{lgE}^{6}$. En contra iría la ausencia de urticaria, angioedema o broncoespasmo. Otra teoría es una reacción autoinmune tipo III que produciría anticuerpos IgG frente a HCT depositándose dichos complejos en la membrana alveolar desencadenando permeabilidad vascular y secundariamente EAP ${ }^{5}$. Algunos autores han observado un descenso en la concentración de IgG y complemento por su posible depósito en la membrana alveolar. Pero probablemente se trate de una reacción idiosincrásica similar a las descritas por otros fármacos como salicilatos y narcóticos ${ }^{7}$.

Esta reacción no parece darse con otras tiazidas ni con la furosemida aunque pertenecen al mismo grupo farmacológico de las sulfonamidas. Ésta puede usarse sin problemas porque no hay evidencia de reacción cruzada ${ }^{7}$. 
Analíticamente presenta leucopenia, trombocitopenia y hemoconcentración transitoria. Nosotros solo observamos leucopenia, explicándose por el secuestro intrapulmonar de granulocitos por la estimulación de IL- $8^{8}$.

El diagnóstico es complicado, dada la inespecificidad de los síntomas. Es necesaria una correcta anamnesis donde la rápida instauración de la clínica tras la toma del medicamento sería de gran ayuda, descartando además el origen cardiogénico. La mayoría de casos publicados con catéter de Swan-Ganz mostraban presiones de enclavamiento y gastos cardiacos normales, así como una función ventricular normal mediante ecocardiografía explicando el origen no cardiogénico. Nosotros no insertamos catéter pulmonar dada la rápida resolución del cuadro, pero ante la clínica, los datos analíticos y ecocardiográficos se diagnosticó de EAP no cardiogénico. La afectación cardiaca manifestada por hipotensión, alteraciones electrocardiográficas y necesidad de aminas puede explicarse por la hipoxia tisular y mediadores químicos como los leucotrienos ${ }^{9}$. Andresen et $\mathrm{al}^{10}$ describen un caso con elevación de NT-pro BNP justificándolo por el daño del ventrículo derecho secundario a vasoconstricción pulmonar hipóxica y la liberación de mediadores vasoactivos, características comunes con el SDRA.

Lo único demostrado para la recuperación es la suspensión de la HCT, además de medidas de soporte y el tratamiento específico del EAP. En general se produce una evolución favorable en menos de $24 \mathrm{~h}$, aunque puede mantenerse alto el gradiente alveolo-arterial de oxígeno, incluso un mes tras la resolución del cuadro clínico por tratarse de un edema intersticial con resolución gradual. Esto se corrobora midiendo la capacidad de difusión del monóxido de carbono, disminuida inicialmente y que alcanza la normalidad aproximadamente al mes ${ }^{10}$.

Es importante, mediante una rigurosa anamnesis, sospechar el daño pulmonar secundario a la HCT dada su gravedad. El diagnóstico en la primera exposición evitaría posteriores recurrencias más graves, y se debe considerar en el diagnóstico diferencial del EAP no cardiogénico o SDRA.

\section{Bibliografía}

1. Hackam DG, Khan NA, Hemmelgarn BR, Rabkin SW, Touyz RM, Campbell NR, et al. The 2010 Canadian Hypertension Education
Program recommendations for the management of hypertension: part 2-therapy. Can J Cardiol. 2010;26:249-58.

2. Bernard GR, Artigas A, Kenneth L, Brigham KL, Carlet J, Falke K, et al. Report of The American-European consensus Conference on Acute Respiratory Distress Syndrome: definitions, mechanisms, relevant outcomes, and clinical trial coordination. Am J Crit Care. 1994;9:72-81.

3. Rubenfeld G, Caldwell E, Peabody E, Weaver J, Martin D, Neff $M$, et al. Incidence and outcomes of acute lung injury. N Engl Med. 2005;353:1685-93.

4. Steinberg AD. Pulmonary edema following ingestion of hydrochlorothiazide. JAMA. 1968;204:167-8.

5. Miroslav S, Jiri C, Jiri K. Hydrochlorothiazide induced pulmonary edema-a rare side effect of common diuretic drug. Int $\mathrm{J}$ Cardiol. 2006;112:251-2.

6. Manso L, Heili S, Fernandez-Nieto M, Sastre B, Sastre J. Basophil activation in two cases of hydrochlorothiazideinduced noncardiogenic pulmonary edema. Allergy. 2010;65: $135-6$.

7. Fine SR, Lodha A, Zoneraich S, Mollera JL. Hydrochlorothiazide induced acute pulmonary edema. Ann Pharmacother. 1995;29:701-3.

8. Ginis I, Mentzer SJ, Faller DV. Characterization of a hypoxia responsive adhesion molecule for leukocytes on human endothelial cell. J Inmmunol. 1995;155:802-10.

9. Goetschalckx K, Ceuppens J, Van Mieghem W. Hydrochlorothiazide-associated noncardiogenic pulmonary oedema and shock: a case report and review of the literatura. Acta Cardiol. 2007;62:215-20.

10. Andresen M, González A, Espino A, Mercado M, Regueira T, Dougnac A. Thiazide induced acute pulmonary edema: report of one case. Rev Med Child. 2007;135:496-500.

B. Maroto Rodríguez*, E. Meyer García-Sípido, N. Chamorro Borraz, C.L. Sanz Sanz y J. Rebollo Ferreiro

Servicio de Medicina Intensiva, Hospital Universitario Severo Ochoa, Leganés, Madrid, España

* Autor para correspondencia. Correo electrónico: bormar77@yahoo.es (B. Maroto Rodríguez).

doi:10.1016/j.medin.2011.02.005 